This is a self-archived - parallel published version of this article in the publication archive of the University of Vaasa. It might differ from the original.

\title{
Forecasting the volatility of biofuel feedstock prices: the US evidence
}

Author(s): Dutta, Anupam; Junttila, Juha; Uddin, Gazi S.

Title: $\quad$ Forecasting the volatility of biofuel feedstock prices: the US evidence

Year: $\quad 2019$

Version: Accepted manuscript

Copyright (C)2019 Society of Chemical Industry and John Wiley \& Sons, Ltd. This is the pre-peer reviewed version of the following article: Dutta, A., Junttila, J., \& Uddin, G.S., (2019). Forecasting the volatility of biofuel feedstock prices: the US evidence. Biofuels bioproducts and biorefining 13(4), 912-919, which has been published in final form at https://doi.org/10.1002/bbb.1981. This article may be used for non-commercial purposes in accordance with Wiley Terms and Conditions for Use of Self-Archived Versions.

\section{Please cite the original version:}

Dutta, A., Junttila, J., \& Uddin, G.S., (2019). Forecasting the volatility of biofuel feedstock prices: the US evidence. Biofuels bioproducts and biorefining 13(4), 912-919. https://doi.org/10.1002/bbb.1981 


\title{
Forecasting the Volatility of Biofuel Feedstock Prices: The US Evidence
}

Anupam Dutta

School of Accounting and Finance, University of Vaasa, Finland

Email: adutta@uwasa.fi

Juha Junttila*

University of Jyväskylä, School of Business and Economics, PO Box 35, 40014 University of Jyväskylä, Finland

Email: juha-pekka.junttila@jyu.fi

\author{
Gazi Salah Uddin \\ Department of Management and Engineering, \\ Linköping University, 581 83, Linköping, Sweden \\ E-mail : gazi.salah.uddin@liu.se
}

\begin{abstract}
\end{abstract}
Given that nowadays $40 \%$ of the US corn crop is used for the biofuel production, there is a growing concern that the upward shift in biofuel production might lead to an increase in food prices. However, it is also obvious that significant growths in biofuel usage have minimized the demand for fossil fuel, and hence, reduced the volume of carbon emissions. It is, therefore, crucial to precisely model the corn market volatility, since such an estimate could play a vital role in stabilizing the food and biofuel market prices. For this purpose, we consider using the information content of the corn implied volatility (CIV) index to predict the corn futures market return volatility. Using symmetric and asymmetric GARCH-class models, we find that the CIV index provides additional information beyond what is contained in the historical volatilities of the corn market returns and the information provided by the CIV index improves the volatility forecasts of the US corn market. These findings could be extremely useful for energy market participants.

Keywords: Bioenergy crop; Corn VIX; Biofuel; GARCH models; Volatility forecast; CIV index

\footnotetext{
${ }^{*}$ Corresponding author
} 


\section{INTRODUCTION}

In the United States, the biofuel usage has increased substantially over the past years. Recent estimates, published by the US Energy Information Administration (EIA), suggest that over the first half of 2017, the weekly ethanol production has averaged 1.02 million barrels per day (b/d), an increase of 5\% over the same period in 2016 and 13\% higher than the previous five-year average.

The US biofuel production is heavily dependent on the corn industry as ethanol is generated from this energy crop. Approximately $40 \%$ of the US corn crop is used for the biofuel production. Given that corn is the leading energy crop for producing biofuel in the United States, there is a growing concern that the upward shift in biofuel production might cause the food prices to increase ${ }^{1}$. However, it is also worth mentioning that such significant growth rates in biofuel usage have lowered the demand for fossil fuels, and hence, reduced the volume of carbon emissions, too. For instance, using a comparable amount of corn ethanol as fuel reduces greenhouse gas emissions by 43 percent compared to fossil fuels ${ }^{\dagger}$. It is, therefore, crucial to precisely model the corn market volatility, since such estimates could play a vital role in stabilizing the food and biofuel markets for their part.

Our paper uses the data from corn futures markets, where analogously to the data on crude oil futures markets, there is strong seasonality in the observations on price quotations ${ }^{\ddagger}$. Trading corn

\footnotetext{
$\dagger$ For more details, see www.growthenergy.org.

* In addition to the seasonality, also analogously to the crude oil markets ${ }^{2}$, at least for the part of ethanol-related production, the spot market for corn crop could be denoted to be a market for the extra corn sold daily, because through-out the year, most of the trading takes place in the futures market. Next to the crude oil futures, the corn market futures are amongst the most actively traded commodity market derivatives in the CBOT. Furthermore, analogously to all global asset markets, commodity futures volume and open interest fluctuate in reaction to political, economic and natural events, including the weather. For example, a drought period experienced this year in many countries can generate strongly trending agricultural futures prices, attracting investors from other futures
} 
1 futures can be fairly tepid during the winter months, while during the summer the market activity

2 is clearly stronger, because corn is planted in the spring and harvested in the fall, so the growing

3 season is when most of the action in corn prices take place. Analogously to many other agricultural

4 products, the winter months usually deal with demand and how much of the harvested crop is sold

5 on a weekly basis. During the summer months the weather problems can be strong, so the corn

6 traders follow tightly every updated weather report. The December futures contract is the new-

7 crop contract each year and it tends to see the most price volatility during the growing season.

8 As noted in previous research ${ }^{3}$, the implied volatility of corn prices is clearly connected to the

9 pricing of ethanol. Therefore, it is important to monitor the price of crude oil and gasoline, too,

10 which determines the demand for ethanol. A cheap corn price and a high price of crude oil often

11 can lead to increased demand for ethanol. However, in this paper, we argue that it is also highly

12 relevant to be able to forecast the variation of prices on the overall corn market, because as an

13 agricultural product, the role of corn in the food production is still very strong, and the role of

14 international trade in corn markets is very high. Therefore, it is important to try to forecast

15 especially the times of strong price variation in the corn markets. Due to the global nature of the

16 corn market, when there is a serious problem with a corn crop, the market tends to panic and buying

17 can cause corn prices to move to a very high level globally due to the strong effects of exports on

18 the price volatility. However, demand tends to fall substantially within a very short time when

19 prices rise to an extreme. Hence, it is of high importance to be able to somehow improve the price

20 volatility forecasts of the corn market.

markets. Hence, volatility of prices tends to rise and fall gradually over long periods because in general, commodity market trends develop slowly, and can in many cases last for at least years rather than weeks or months. This kind of behavior introduces also the possibility of asymmetries in the data generating processes of the corn futures prices. 
1 Modeling volatility plays a crucial role in risk assessment procedures. Proper knowledge of

2 volatility is also important for market-timing decisions, pricing of options and determining market

3 risk and hedge ratios ${ }^{4}$. It is, therefore, essential to provide accurate forecasts of volatility. Given

4 that corn is the main feedstock for the US biofuel industry, understanding corn market volatility is

5 of paramount importance when designing the US bioenergy policy. Since commodity prices (oil,

6 corn etc.) have been highly volatile over the past years, it is useful to generate reliable forecasts

7 for the corn market volatility. Moreover, earlier studies ${ }^{5,3}$ show that an increase in corn price

8 volatility leads to an upturn in the US ethanol price index. Hence, a proper measure of corn market

9 volatility is vital for developing effective strategies to adjust the ethanol market risk. It has also

10 been argued that unprecedented volatility in world agricultural commodity prices creates much

11 uncertainty and risk for all market participants, and makes both short-term and longer-term

12 planning difficult ${ }^{6}$. A major issue, therefore, is whether and how agricultural price volatility can

13 be predicted.

14 To this end, we consider using the corn market implied volatility (CIV) index for forecasting the

15 corn futures market realized return volatility. Previously it has been argued ${ }^{7}$ (without explicit

16 statistical testing) that the application of CIV index could provide better volatility forecasts for the

17 corn market which will, in turn, produce a more accurate estimate for the corn market risk.

18 Therefore, corn VIX is used as an additional variable in our forecast exercise. Note that the corn

19 VIX is defined as a benchmark of expected short-term (30 days) market volatility and provides a

20 forward-looking measure of corn price volatility. Moreover, the CIV index also provides a

21 benchmark upon which futures and option contracts on corn volatility can be written. Thus, the

22 corn VIX carries benefits for both policymakers and academics alike; first as an updated proxy for

23 the markets expectation of future corn market volatility, and, as such, is regarded of high value for 
1 day-to-day trading decisions, and second, it provides an insight into risk and return patterns. On

2 the whole, the direction of the association between the CIV index and the realized volatility of US

3 corn futures prices may allow us to measure the corn market risk more precisely.

4 Our paper contributes to the extant literature in several aspects. First, based on our knowledge, this

5 is the first attempt to use the information content of CIV index time series in modeling and

6 forecasting the US corn market volatility. Considering the volatility index is important, since

7 implied volatilities reveal more information than do the historical price series. Additionally, the

8 CIV index includes both historical volatility information and investors' expectation of the future

9 market conditions, and thus, appears as a superior indicator of the corn price uncertainty. While a

10 strand of literature has investigated the role of the stock market VIX index in predicting stock

11 market return variances, much less work has been done in this field for commodity markets.

12 Therefore, there is a need to conduct further empirical works in order to verify whether using the

13 information on commodity VIX quotations provides more accurate measures for the volatility

14 forecasts. It is also worth mentioning that the results of the existing literature are somewhat mixed.

15 In earlier studies it has been shown ${ }^{8,9,4}$ that the use of the stock market VIX improves the volatility

16 forecasts. On the other hand, some researchers ${ }^{10,11}$ document that the VIX index does not provide

17 an efficient volatility forecast. Thus, the prior literature has yet to agree on the usefulness of VIX

18 when forecasting the volatility and hence, the predictive power of VIX merits further investigation.

19 In this study, we examine if the information content of the corn VIX is useful for obtaining a more

20 precise estimate of the conditional variance for the US corn market.

21 Second, our work extends the previous studies on risk spillovers by investigating if the corn market

22 implied volatility has any significant effects on the realized volatility of the corn futures returns. 
1 Methodologically, we employ two different GARCH-class models and consider the CIV index as

2 an exogenous variable in the conditional variance equations of the different GARCH processes.

3 We find that the CIV index provides additional information beyond what is contained in the

4 historical volatilities of the corn market returns. Notably, the inclusion of CIV index plays a vital

5 role in modeling the conditional variance of the corn futures returns more precisely. These results

6 should be useful for portfolio diversification, bioenergy policy planning and risk management,

7 since the CIV index seems to be a significant futures market risk indicator.

\section{$8 \quad 2$ LITERATURE REVIEW}

9 A large number of studies has investigated the dynamics of corn market volatility over the years.

10 In this section, we briefly review some of the important contributions relevant to our study. Some

11 of them ${ }^{12}$, have examined the predictive ability of option implied volatility in corn, wheat and

12 soybeans futures contracts, and shown that option based implied volatility has substantial

13 predictive power for subsequent realized volatility. Others ${ }^{7}$ have estimated model-free option

14 implied variance in the corn market. These studies find that the model-free variance is a more

15 effective estimator of future variance, compared to backward looking methods of estimating future

16 variance or forward looking option implied volatility methods.

17 More recently ${ }^{6}$, researchers have investigated empirically the predictive power of model-free

18 option implied variance and skewness in wheat, maize and soybeans derivative markets, and found

19 that an option-implied risk-neutral variance measure outperforms the historical variance as a

20 predictor of the future realized variance for these three commodities. In addition, a methodology

21 for constructing a risk-adjusted implied volatility measure of corn futures has been recently 
1 developed ${ }^{13}$. These findings suggest that the risk-adjusted volatility is unbiased, informationally

2 efficient, and has superior predictive power over the alternatives considered.

3 Another line of research has explored whether the corn market volatility is affected by the energy

4 market volatility ${ }^{14}$ via volatility transmissions between the US oil, corn, and wheat future prices

5 based on applying a vector ARCH model. The results reveal the existence of volatility spillover

6 from crude oil prices to corn prices. Employing the univariate EGARCH and multivariate BEKK-

7 GARCH models, one study ${ }^{15}$ has examined the volatility spillovers among the Chinese crude oil,

8 corn and fuel ethanol markets. These authors document that the oil market volatility plays a crucial

9 role in explaining the volatility of corn prices. Furthermore, a recent study ${ }^{16}$ shows that the crude

10 oil market volatility is a significant factor causing changes in both the corn and wheat price

11 volatilities.

12 However, none of the above-mentioned studies has explicitly used the information provided by

13 the CIV index time series when modeling and forecasting the corn price variability. In this paper,

14 we aim to fill this void. Considering the information content of the corn VIX is important given

15 that the implied volatilities represent an improvement among the existing measures which only

16 contain historical volatility information, and thereby, fall short of accounting for investors'

17 expectations of future market conditions. Furthermore, implied volatilities represent a forward-

18 looking measure of the market uncertainty as well. One can thus postulate that the use of corn

19 implied volatilities would help to improve the predictive power of the GARCH-type models

20 applied for the corn market futures returns.

21 


\section{MATERIALS AND METHDOS}

\section{$2 \quad 3.1$ Data}

3 Our data include daily corn futures prices and the CIV index published by the CBOT, and the

4 sample period ranges from June 2, 2011 to December 31, 2017. The beginning of the sample period

5 is based on the availability of the CIV index time series. All the information is retrieved from the

6 Datastream database.

7 Notably, like other implied volatility series, the CIV index is also used as a measure of market

8 risk. To be exact, it estimates the market's expectation of 30-day volatility of corn prices by

9 applying the VIX methodology to options that trade on corn futures. Thus the CIV index has emerged as an effective tool for market participants to directly track the volatility in corn prices.

12 Due to the strong changes in the global demand and supply conditions, the spot price of the US 13 corn market reached its all-time high of 849 USD/Bushel in August 2012, and in our data, the all14 time high for the futures price was achieved on $21^{\text {st }}$ of August 2012 at the level of 831.25 $15 \mathrm{USB} /$ Bushel. As we see from Figure 1, the changes in the market conditions clearly have been a root for the clustering (GARCH-type) behavior of futures market return volatility at that time, and

17 around other times of strong variation in the market prices, too. However, it is also obvious from 18 the figure that the CIV index clearly might have a role here as a prominent forecasting variable for 19 the futures market. As observed just prior to the August 2012 hike, and for many other occasions 20 in our data set, especially the increasing values of CIV seem to be strongly in connection with the 21 forthcoming strong changes in the returns in the futures market. Hence, the behavior of the 
1 analyzed time series in Figure 1 gives us clearly a good background to introduce the CIV index as

2 a new prominent forecasting variable when modeling the volatility of corn market prices/returns.

\subsection{GARCH models}

4 Methodologically, we consider two different specifications of the GARCH-type models to analyze

5 the corn market volatility. Using GARCH-type approaches to model and forecast the energy prices

6 is very common in the existing literature ${ }^{17}$. Our analyses are based on the standard symmetric

7 GARCH model ${ }^{18}$, and the exponential GARCH (EGARCH) model ${ }^{19}$.

8 The first step in utilizing these models constitutes of the definition of the conditional mean 9 equation as

10

11

12

13

14

15

16

17

18

19

20

21

22

23 indicates the conditional variance at time $t-1$. or a Student's $t$ distribution. equation (1):

$$
r_{t}=\pi+\phi r_{t-1}+\varepsilon_{t}
$$

i.e., as an $\mathrm{AR}(1)$-process, with the constant term $\pi$, where $r_{t}$ denotes the daily log return of the US corn futures market at time $t$. We assume that the error term $\varepsilon_{t}$ follows either a normal distribution

Now the $\operatorname{GARCH}(1,1)$ model takes the following form for the variance of the error term in

$$
h_{t}^{2}=\omega+\alpha \varepsilon_{t-1}^{2}+\beta h_{t-1}^{2}
$$

In Equation (2), in addition to the constant term $(\omega), \alpha$ and $\beta$ are the GARCH parameters, $h_{t}^{2}$ refers to the conditional variance at time $t, \varepsilon_{t-1}^{2}$ indicates the volatility news at time $t-1$ and $h_{t-1}^{2}$ 4 
1 Next, a nonlinear, asymmetric specification of the conditional variance as an EGARCH

2 specification is given by:

3

4

5

6 In the above specification, if $\gamma=0$, the model is symmetric. If $\gamma<0$, then good volatility news

$$
h_{t}^{2}=\omega+\alpha\left|\frac{\varepsilon_{t-1}}{h_{t-1}}\right|+\gamma \frac{\varepsilon_{t-1}}{h_{t-1}}+\beta h_{t-1}^{2}
$$

will generate more volatility than the bad news and vice versa. Finally, our simple extension of the GARCH(1,1) model involving the corn market implied volatility index (CIV) is based on representation

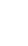

$$
h_{t}^{2}=\omega+\alpha \varepsilon_{t-1}^{2}+\beta h_{t-1}^{2}+\theta C I V_{t-1}^{2}
$$

where the implied volatility index values are also lagged one period, as are the other components in the symmetric GARCH( $(1,1)$ model. Furthermore, the same extension applies to the asymmetric version, i.e., the EGARCH process.

\section{RESULTS AND DISCUSSIONS}

We first discuss the findings from the conventional $\operatorname{GARCH}(1,1)$ analysis. The results of the extended GARCH-class models where the CIV index is incorporated as an explanatory factor in the GARCH variance equations will follow. The findings reported in Table 1 reveal that the GARCH parameters in each model are highly significant indicating that strong ARCH and GARCH effects exist in the corn market returns. In addition, the sum of the ARCH and GARCH parameters further suggests a high degree of persistence in the corn market return volatility implying that the volatility shocks today will influence the expectation of volatility many periods in the future. In other words, volatility is persistent if today's return has a significant impact on the future volatility. Therefore, predicting the future volatility of the US corn market seems to depend 
1 on today's corn futures returns. Determining the degree of volatility persistence is thus important

2 considering that the past volatility explains current volatility ${ }^{20}$.

\section{3 [TABLE 1 HERE]}

4

5 Next, we aim to verify whether the lagged values of the CIV index have any substantial influence over the corn market futures volatility. According to our results, the lagged CIV values do have a significant impact on the volatility of corn futures returns as the null hypothesis $\left(\mathrm{H}_{0}: \theta=0\right)$ is rejected even at $1 \%$ risk level in all cases. Hence, it can be inferred that the information provided by the CIV index should not be overlooked when modeling the corn futures market volatility.

Moreover, our findings also suggest that the degree of volatility persistence is reduced in the extended models. For instance, the estimates of the original GARCH specification provide evidence of high volatility persistence (the sum of $\alpha$ and $\beta$ is close to 1 ), whereas the corresponding estimates of the extended GARCH model confirm that there is a significant drop in the volatility persistence. Such reduction in the persistence could be due to the fact, that the CIV index captures more persistence than the GARCH parameters. One could also expect that the information conveyed by the corn market implied volatilities may reduce the effects from the conditional variance at $(t-1)$ upon the conditional variance at $(t)$, thereby reducing the persistence ${ }^{21}$. It is noteworthy that our results do not change much when the error term in the GARCH specification follows a student's $t$ distribution. However, one discrepancy is that the GARCH parameters have now become insignificant implying that the CIV index seems to capture all the persistence in the corn futures market volatility.

The results further demonstrate that the log-likelihood value increases when the extended GARCH model is adopted. Based on these results, we can conclude that considering the CIV index as an 
1 exogenous variable in the GARCH model provides a better estimate of the conditional volatility

2 of the corn market in comparison to the base-line specification.

3 [TABLE 2 HERE]

4 With a view to assessing the robustness of the results, we also estimate the EGARCH models

5 assuming that the error term follows either a normal or Student's $t$ distribution. The results shown

6 in Table 2 are consistent with those reported in Table 1. In other words, the CIV index still exerts

7 a significant impact on the corn market futures volatility. More importantly, when including the

8 CIV index to the volatility equation, a significant drop is observed in the volatility persistence.

9 The $\gamma$ coefficient, which measures the asymmetric news impact, appears to be strongly significant 10 implying that there exists asymmetric effect of so-called 'bad' or 'good' news on the US corn 11 market. Hence, bad news and good news do not have the same effect on the corn market volatility.

12 In addition, the sign of $\gamma$ is negative in the EGARCH process, implying in fact that there are

13 leverage effects in the US corn market. In other words, negative shocks (bad news) generate more

14 volatility than do the positive shocks (good news), so negative innovations are more destabilizing 15 than positive innovations.

17 Finally, we investigated whether the CIV index carries important information that improves the 18 volatility forecasts for the corn market. To serve this purpose, we estimated the following 19 regression equation:

$$
\sigma_{t+1}^{2}=a+b \sigma_{f, t}^{2}+\xi_{t}
$$

21 where $\sigma_{t+1}^{2}$ is the realized volatility of the corn futures market returns at time $t+1, \sigma_{f, t}^{2}$ represents

22 the volatility forecast at time $t$ and $\xi_{t}$ defines the forecast error term. Following previous research 
121 , the squared excess returns are used as a measure of the realized volatility. In addition, $\sigma_{f, t}^{2}$ is

2 proxied by either the conventional GARCH forecast or the forecast from an extended GARCH

3 model. The forecast performance of these models is compared on the basis of $\mathrm{R}^{2}$ values from the

4 regression equation (7).

5 [TABLE 3 HERE]

6 Table 3 exhibits the results of our forecast performance analysis. The results show that when the

7 squared CIV is included in the GARCH process, the values of $\mathrm{R}^{2}$ statistics tend to increase. For

8 instance, when the error follows a normal distribution, the $\mathrm{R}^{2}$ statistics amount to 0.0543 for the

9 simple GARCH model and to 0.0900 for the extended version. This finding holds for the Student's

$10 t$ error distributions as well. We thus conclude that the predictive ability of the extended GARCH

11 process is better than that of the basic GARCH process, indicating that including the CIV index to

12 the volatility model improves the volatility forecasts of the US corn futures market returns.

13 Our findings are in line with those reported in some earlier studies ${ }^{8,9,4}$ for the stock markets These

14 studies also find that the use of implied volatility indexes improves the volatility forecast

15 performance. However, as the CIV index is a relatively new measure of corn market uncertainty,

16 further research in this area is needed to understand the dynamics in this new volatility index.

17 Overall, the results of this study could help the policymakers to predict the future corn market

18 trends and hedge the market risk. To this end, the application of CIV index will improve the

19 prediction of energy crop volatility and enhance market participants' ability to more accurately

20 measure the price risk in the US corn market. In addition, our research should receive special

21 attention from those investors who make use of new financial tools to hedge the corn market price

22 volatility risk and are potentially interested in futures and option trading on corn VIX. 
1 Notably, corn production plays a major role in the US economy. It is one of the largest corn

2 producers with 96,000,000 acres of land being used for corn production. In fact, the US is currently

3 ranked as the first in the world in corn production, and approximately $13 \%$ of its annual crop is

4 exported $^{\S}$. In the $2016 / 2017$ crop marketing year, the country grows more than 14.6 billion bushels

5 (385 million metric tons) of corn and about 17 percent of this production was exported to more

6 than 80 different countries. Moreover, roughly 50\% of the corn produced in the US is used as

7 animal feed and a large portion is used for generating ethanol. As a result, rising corn prices have

8 caused the costs of feeding livestock and biofuel production to go upwards. In addition, increased

9 corn volatility has caused the prices of other crops to become increasingly unstable ${ }^{22}$. It is,

10 therefore, indispensable to obtain a reliable forecast for corn price volatility. A precise measure of

11 corn volatility could then estimate the market risk more efficiently and further make the allied

12 markets (such as biofuel and crop markets) more stable. To this end, our findings suggest that

13 using corn VIX as an exogenous variable in the GARCH volatility equation clearly improves the 14 volatility prediction performance.

\section{CONCLUSIONS}

16 On the whole, we document that taking the CIV index into consideration is crucial for obtaining a

17 precise estimate of the conditional variance for the US corn market futures returns. The precise estimation of volatility is crucial for analyzing the risk transmission amongst the relevant markets. Hence, good knowledge of the volatility forecasting is essential for developing appropriate policies 20 to adjust the market risk.

\footnotetext{
$\S$ For more details, see http://www.grains.org/ buyingselling/corn.
} 
1 The findings of this study could be useful for energy economists and policymakers to improve

2 their hedging strategies in order to moderate the corn market risk. Hedging the corn market risk

3 properly could create a superior environment to promote the production of ethanol, too, which

4 would then limit the dependence on the fossil-based fuels.

5 Moreover, our findings confirm that the CIV index induces volatility to the US corn market. It is

6 thus important to adopt effective measures to manage the price volatility in the corn market. One

7 such strategy could be to promote better market monitoring systems by improving the functioning

8 of the corn futures market. A more developed and improved (efficient) futures market could then

9 limit the corn price risk more efficiently and further make the allied (such as biofuel, like the

10 ethanol) markets more stable.

11 The results of our empirical research have important implications for the investors as well. As

12 various structured investment products are traded on the basis of corn market prices and returns,

13 the market participants could use our findings for making appropriate asset allocation decisions.

14 Furthermore, the results could also be helpful for the purposes of hedging the risk of portfolios

15 comprising of food and biofuel investments.

16 Future research could focus on assessing the explanatory power of other volatility measures such

17 as the oil VIX (OVX) and the US equity market VIX. Since rising oil prices might encourage a

18 significant growth in the ethanol production, for example the information content of the oil VIX

19 (OVX) could possibly be utilized to forecast the corn market volatility. In addition, due to the

20 increasing degree of financialization of all the commodity derivatives markets, the US stock

21 market VIX as an indicator of the global financial market uncertainty could help in predicting the

22 risk development in the corn markets, too. 
1. Dutta, A, Cointegration and nonlinear causality among ethanol-related prices: evidence from Brazil. GCB Bioenergy 10/5: 335-342 (2018).

2. Junttila, J., Pesonen, J and Raatikainen, J, Commodity market based hedging against stock market risk in times of financial crisis: The case of crude oil and gold. Journal of International Financial Markets, Institutions and Money 56: 255-280 (2018).

3. Dutta, A, Bouri, E, Junttila, J and Uddin, GS, Does corn market uncertainty impact the US ethanol prices?, GCB Bioenergy 10/9: 683-693 (2018).

4. Kambouroudis, DS, and McMillan DG, Does VIX or volume improve GARCH volatility forecasts? Appl Econ, 48: pp. 1-19 (2016).

5. Serra T, Zilberman D, Gil J, Price volatility in ethanol markets. European Review of Agricultural Economics, 38: 259-280 (2011).

6. Triantafyllou, A., Dotsis, G. and Sarris, AH, Volatility forecasting and time varying variance risk premiums in grains commodity markets, Journal of Agricultural Economics 66(2): 329-357 (2015).

7. Wang, Z, Fausti, SW, Qasmi, BA, Variance Risk Premiums and Predictive Power of Alternative Forward Variances in the Corn Market. Journal of Futures Markets 32: 587-608 (2012).

8. Corrado, C. J., and Miller, Jr. TW, The Forecast Quality of CBOE Implied Volatility Indexes. The Journal of Futures Markets 25: 339-373 (2005).

9. Dennis, P., S. Mayhew, and Stivers, C, Stock Returns, Implied Volatility Innovations, and the Asymmetric Volatility Phenomenon. Journal of Financial and Quantitative Analysis 41: 381-406 (2006).

10. Becker, R., A. E. Clements, and White SI, On the Informational Efficiency of S\&P500 Implied Volatility. The North American Journal of Economics and Finance 17: 139-153 (2006).

11. Ederington, L. H., and Guan, W, Is Implied Volatility an Informational Efficient and Effective Predictor of Future Volatility? Journal of Risk 4: 29-46 (2002).

12. Simon, D P, Implied volatility forecasts in the grains complex, The Journal of Futures Markets 22: 959-81 (2002).

13. Wu, F, Myers, RJ, Guan, ZF, Wang, ZG, Risk-adjusted implied volatility and its performance in forecasting realized volatility in corn futures prices, J. Empir. Finance 34: 260-274 (2015).

14. Du, X., Yu, C., and Hayes, D, Speculation and volatility spillover in the crude oil and agricultural commodity markets: a Bayesian analysis. Energy Econ. 33 (3): 497-503 (2011).

15. Wu, H, Li, S, Volatility spillovers in China's crude oil, corn and fuel ethanol markets. Energy Policy 62: 878-886 (2013).

16. Mensi, W, Tiwari, A., Bouri, E., Roubaud, D. and Al-Yahyaee, KH, The dependence structure across oil, wheat, and corn: a wavelet-based copula approach using implied volatility indexes Energy Econ., 66: 122-139 (2017)

17. Kang SH, Kang SM and Yoon SM, Forecasting volatility of crude oil markets. Energy Economics 31: 119-125 (2009).

18. Bollerslev T, Generalized autoregressive conditional heteroskedasticity. Journal of Econometrics 31: 307-327 (1986).

19. Nelson DB, Conditional heteroskedasticity in asset returns: A new approach. Econometrica 59: 347-370 (1991).

20. Charles A., and Darné O, Volatility persistence in crude oil markets. Energy Policy 65: 729-742 (2014). 
1

2

3

4

5

7

8 Acknowledgements:

9 The third author is thankful for the financial support provided by the Jan Wallander and Tom Hedelius Foundations

10

11

12

13

14

15

16

17

18

19

20

21

22

23

24

25

26

27

28

29 
Table 1: Results from the symmetric conditional volatility models

\begin{tabular}{|l|c|c|c|c|}
\hline Parameters $\backslash$ Models & GARCH-N & GARCH-t & Ex. GARCH-N & Ex. GARCH-t \\
\hline \multicolumn{1}{c|}{$\boldsymbol{\omega}$} & $0.009812^{* * *}$ & $0.005933^{* *}$ & $-0.023964 * *$ & $-0.029488^{*}$ \\
\hline $\boldsymbol{\beta}$ & $0.076584 * *$ & $0.058804 * * *$ & $0.041357^{* *}$ & 0.025825 \\
\hline $\boldsymbol{\theta}$ & $0.902750^{* * *}$ & $0.928345^{* * *}$ & $0.317404 * * *$ & 0.034414 \\
\hline Log-likelihood & & & $0.000426 * * *$ & $0.000615 * * *$ \\
\hline AIC & -1644.49 & -1590.99 & -1577.52 & -1547.23 \\
\hline BIC & 1.9236 & 1.8623 & 1.8466 & 1.8125 \\
\hline
\end{tabular}

3 Notes: In this table, $\theta$ represents the regression coefficient on the CIV index. Ex. GARCH $(1,1)$ refers to

4 the GARCH model including the past values of the squared CIV term. ***,** and * refer to the significant 5 parameter estimates at $1 \%, 5 \%$ and $10 \%$ levels respectively. 
2

3

17

\begin{tabular}{|c|c|c|c|c|}
\hline Parameters $\backslash$ Models & EGARCH-N & EGARCH-t & \multicolumn{1}{l|}{$\begin{array}{l}\text { Ex. EGARCH- } \\
\mathbf{N}\end{array}$} & Ex. EGARCH-t \\
\hline $\boldsymbol{\omega}$ & $-0.153904^{* * *}$ & $-0.118371^{* * *}$ & $-1.055069^{* * *}$ & $-1.542762^{* * *}$ \\
\hline $\boldsymbol{\alpha}$ & $0.170700^{* * *}$ & $0.138074 * * *$ & $0.105648^{* * *}$ & 0.071790 \\
\hline $\boldsymbol{\beta}$ & $0.972129 * * *$ & $0.984649 * * *$ & $0.517379 * * *$ & 0.251651 \\
\hline $\boldsymbol{\gamma}$ & $-0.025203^{* * *}$ & -0.009032 & $-0.093752^{* * *}$ & $-0.79656^{* *}$ \\
\hline $\boldsymbol{\theta}$ & & & $0.000693 * * *$ & $0.001042^{* * *}$ \\
\hline Log-likelihood & -1642.16 & -1587.04 & -1595.31 & -1560.58 \\
\hline AIC & 1.9220 & 1.8589 & 1.8685 & 1.8292 \\
\hline BIC & 1.9411 & 1.8811 & 1.8908 & 1.8546 \\
\hline
\end{tabular}

\section{Table 2: Results from the asymmetric conditional volatility models}

Notes: See Table 1. In addition, Ex. EGARCH $(1,1)$ refers to the EGARCH model including the squared CIV term.

0

21 
Table 3: Volatility forecasting performance

3

\begin{tabular}{|c|l|l|l|l|}
\hline Parameters $\backslash$ Models & GARCH-N & GARCH-t & Ex. GARCH-N & Ex. GARCH-t \\
\hline $\boldsymbol{a}$ & $0.0751^{*}$ & 0.0622 & -0.0102 & -0.0108 \\
$\boldsymbol{b}$ & $0.8151^{* * *}$ & $0.8456^{* * *}$ & $1.0337^{* * *}$ & $1.0382^{* * *}$ \\
\hline $\mathbf{R}^{\mathbf{2}}$ & 0.0543 & 0.0546 & 0.0900 & 0.0889 \\
\hline
\end{tabular}

4 Notes: This table reports the predictive ability of the $\operatorname{GARCH}(1,1)$ models based on the $\mathrm{R}^{2}$ statistics from

5 regression equation (7), i.e. $\sigma_{t+-1}^{2}=a+b \sigma_{f, t}^{2}+\xi_{t}$ described in the text. Ex. GARCH refers to the

6 GARCH model including the squared CIV term. $* * *$ and $*$ refer to the parameters that are significant at

$7 \quad 1 \%$ and $10 \%$ levels, respectively. 


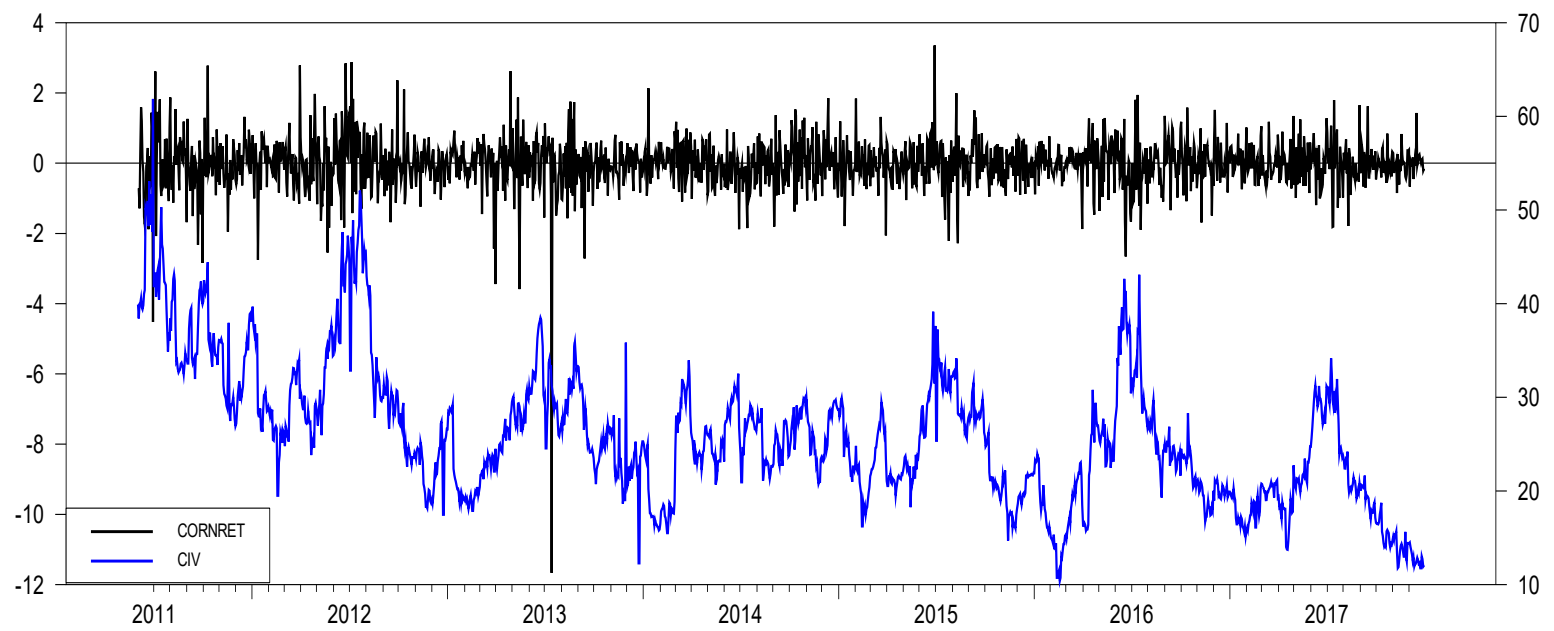

Figure 1. Time series of corn futures returns (CORNRET, left axis) and the corn market implied volatility index (CIV, right axis). Source: Datastream International 